\title{
Success of applying early goal-directed therapy for septic shock patients in the emergency department
}

This article was published in the following Dove Press journal:

Open Access Emergency Medicine

14 January 2016

Number of times this article has been viewed

\section{Panita Worapratya' \\ Apisit Wanjaroenchaisuk ${ }^{2}$ \\ Jutharat Joraluck ${ }^{3}$ \\ Prasit Wuthisuthimethawee' \\ 'Department of Emergency Medicine, Songklanagarind Hospital, Faculty of Medicine, Prince of Songkla University, Songkhla, ${ }^{2}$ Emergency Department, Samitivej Thonburi Hospital, Bangkok, ${ }^{3}$ Emergency Department, Hatyai Hospital, Hatyai, Songkhla, Thailand}

Correspondence: Panita Worapratya Department of Emergency Medicine, Songklanagarind Hospital, Prince of Songkla University, I5 Karnjanavanich Road, Hat Yai, Songkhla 90I I0, Thailand Tel $+667445 \quad 1705$

Fax +66 74451704

Email pikkokung@yahoo.com
Background: Since early goal-directed therapy (EGDT) became standard care in severe sepsis and septic shock patients in intensive care units many years ago, we suppose that the survival rate of severe sepsis and septic shock patients improves if the resuscitative procedure is quickly implemented and is initiated in the emergency room.

Objective: We aimed at recording emergency department time to improve our patient care system as well as determine the rate at which EGDT goals can be achieved. The second analysis is to find out how much we can improve the survival rate.

Methods: This was a prospective observational study in an emergency room setting at a tertiary care facility where EGDT was applied for resuscitation of severe sepsis and septic shock patients. The data recorded were the initial vital signs, APACHE II (Acute Physiology and Chronic Health Evaluation II) score, SAP II (Simplified Acute Physiology II) score, SOFA (Sequential Organ Failure Assessment) score, time at which EGDT goals were achieved (central venous oxygen saturation $\left[\mathrm{ScVO}_{2}\right]>70 \%$ ), initial and final diagnosis, and outcome of treatment. The $t$-test and Mann-Whitney $U$-test were used to compare between the achieved goal and nonachieved goal groups.

Results: There were 63 cases of severe sepsis in the study period. Only 55 patients submitted a signed consent form and had central line insertion. Twenty-eight $(50.9 \%)$ cases were male. Thirty-nine (70.9\%) patients achieved the goal, and the mean SAP II score was 8 . There were no statistically significant differences between the two groups $(P$-value $=0.097)$. Thirty of the 39 patients $(70.9 \%)$ survived in the achieved goal group, which was a statistically significant improvement of the survival rate when compared with only one of 16 patients $(6.3 \%)$ surviving in the nonachieved goal group $(P<0.001)$.

Keywords: sepsis, septic shock, early goal-directed therapy, emergency room

\section{Background}

The original article by Rivers et $\mathrm{al}^{1}$ published in 2001 showed the huge benefit of a lower mortality rate in severe sepsis and septic shock patients from $46.5 \%$ to $30.5 \%$. Early goal-directed therapy (EGDT) is a sepsis cardiovascular support protocol aimed at early hemodynamic optimization, which became standard treatment for severe sepsis and septic shock patients according to the Surviving Sepsis Campaign guidelines for the management of severe sepsis and septic shock in $2004 .^{2}$ The original research was conducted in a critical care unit; however, the principles are to bring blood circulation back to normal as soon as possible. In practice, septic shock patients present commonly in the emergency room. Therefore, the implementation of EGDT in the emergency room is essential. Recent studies show that the implementation of EGDT in the emergency room can be achieved and that it has benefits. ${ }^{3,4}$ 
Songklanagarind Hospital is a tertiary care and referral center in southern Thailand. There are more than 42,000 cases each year. in the emergency room. EGDT was implemented in the emergency room of Songklanagarind Hospital in 2010. This study was conducted to determine the success rate of applying EGDT in the emergency room.

The primary outcome is to achieve the EGDT goals, which are defined as central venous pressure (CVP) $\geq 8 \mathrm{mmHg}$, mean arterial pressure (MAP) $\geq 65 \mathrm{mmHg}$, and central venous oxygen saturation $\left(\mathrm{ScvO}_{2}\right) \geq 70 \%$. The secondary outcome is to determine to what extent the survival rates can improve.

\section{Methods}

This was a prospective observational study held in the emergency department between April 1 and September 30, 2013. The study was approved by the research quality and safety control committee of Prince of Songkla University. Only newly diagnosed septic shock patients who were of age $\geq 18$ years, received EGDT, and submitted signed written consent forms were enrolled. The recorded data included the chief compliant, initial vital signs, past medical history, laboratory tests, initial and final diagnoses, severity scores (Sequential Organ Failure Assessment [SOFA], Simplified Acute Physiology II [SAP II], and Acute Physiology and Chronic Health Evaluation [APACHE II]), time to reach the goals (CVP $\geq 8 \mathrm{mmHg}, \mathrm{MAP} \geq 65 \mathrm{mmHg}$, and $\mathrm{ScvO}_{2} \geq 70 \%$ ), and the results of treatment (death or improved). Only the cases of those patients or authorized representatives who signed a written consent form and had complete medical research charts were enrolled into the study. All others were excluded.

As soon as the patient was diagnosed as having septic shock, the severe sepsis and septic shock campaign guideline of 2008 (Figure 1) ) $^{5}$ was followed and parameters were recorded. Volume resuscitation, central venous catheter insertion (subclavian vein or internal jugular vein), and isotonic crystalloid were used to achieve a CVP of $8-12 \mathrm{mmHg}$. Vasopressors were added if necessary to reach the target MAP of $65 \mathrm{mmHg}$. Packed red blood cells and/or dobutamine were given when needed to reach the target $\mathrm{ScvO}_{2}$ of $\geq 70 \%$. The times to reach the goals were also recorded.

After the time to reach the goals was recorded, the patients were divided into two groups: achieved goal group and nonachieved goal group. The achieved goal

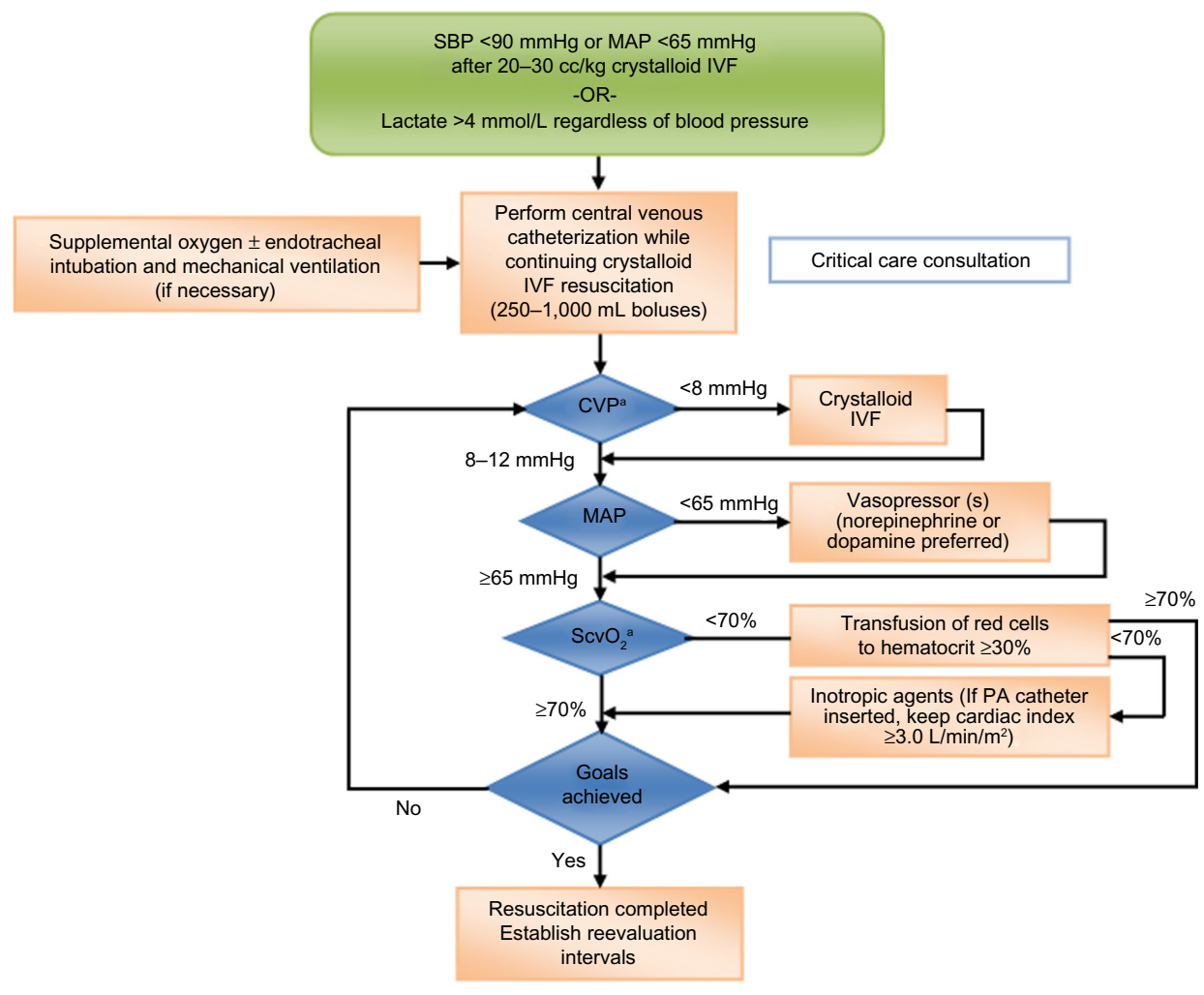

Figure I Early goal-directed-therapy guideline.

Notes: This protocol should be initiated within I hour of presentation (or severe sepsis identification) and continued for at least the first 6 hours of resuscitation. alf PA catheter is inserted, PCWP target of $12-15 \mathrm{mmHg}$ replaces CVP target, and $\mathrm{ScvO}_{2} \geq 70 \%$ replaces $\mathrm{ScvO}_{2}$ target.

Abbreviations: SBP, systolic blood pressure; MAP, mean arterial pressure; IVF, intravenous fluid; PA, pulmonary artery; PCWP, pulmonary capillary wedge pressure; CVP, central venous pressure; $\mathrm{ScvO}_{2}$, central venous oxygen saturation. 
group included those patients who had attained an $\mathrm{ScvO}_{2} \geq 70 \%$ within 6 hours, and any patient who could not achieve the aforementioned $\mathrm{ScvO}_{2}$ level within 6 hours was allocated to the nonachieved goal group. The emergency physician who took care of the septic shock patients had to record the actual time the EGDT goal was achieved, while the results of the treatment (death or improved) were recorded by a research assistant. The primary end point of this study was the achieved EGDT goal rate, represented as a percentage, and the secondary end point was the mortality rates of the two groups: achieved and nonachieved goal groups. For the statistical analysis, the $t$-test and Mann-Whitney $U$-test were applied.

\section{Results}

There were 101 initially diagnosed severe sepsis and septic shock patients between April 1 and September 30, 2013, according to the definition of the severe sepsis and septic shock campaign $2008,{ }^{5}$ who were aged $\geq 18$ years and registered in the EGDT registry, but only 55 patients were enrolled in this study. Of the 46 patients not enrolled in this study, 24 refused central venous catheter insertion, 17 were referred to other hospitals, four were finally diagnosed as other causes of shock, and one was aged under 18 years. Twenty-eight $(50.9 \%)$ of the 55 enrolled patients were male, and the mean age was 65.1 years. In 17 cases (30.9\%), the cause of infection could not be identified. Among 38 patients, 20 (36.4\%) were diagnosed as having pneumonia, nine (16.36\%) as having infective gastroenteritis and hepatobiliary tract infection, eight (14.5\%) as having urinary tract infection, six as having $(10.9 \%)$ skin and soft tissue infection, two as having spontaneous bacterial infection, and one as having osteomyelitis. Hemoculture results were reported as positive in $33(60 \%)$ cases. Twenty-two (40\%) patients had acute renal failure, 23 (41.8\%) needed mechanical ventilator, and $52(94.5 \%)$ needed vasoactive agent. The mean serum lactate in the achieved goal group was $3.6 \mathrm{mmol} / \mathrm{L}$, and the mean serum lactate in the nonachieved goal group was $5.3 \mathrm{mmol} / \mathrm{L}(P=0.498)$. The demographic data are listed in Tables 1 and 2.

\section{Primary analysis}

There were 39 patients who achieved the EGDT goals and 16 who did not achieve the EGDT goals within 6 hours. The mean SAP II, APACHE II, and SOFA scores in the achieved and nonachieved EGDT goal groups (Table 3) were not statistically significantly different between the two groups. The mean times to receive antibiotics in the achieved goal group and nonachieved goal group were 64 and 58 minutes, respectively, with no statistical significance between the two groups $(P=0.405)$.

Table 4 lists the resuscitative procedures and agents that were used in the two groups. In the achieved and nonachieved goal groups, vasoactive agents were used in $97.4 \%$ and $87.5 \%$ of the cases, respectively, and mechanical ventilation was applied in $41.0 \%$ and $43.8 \%$ of the cases, respectively, which showed no statistical significance. However, blood transfusion between the achieved and nonachieved goal groups was significant (12.8\% vs $37.5 \%$, respectively) $(P<0.01)$.

Table I Demographic data

\begin{tabular}{|c|c|c|c|c|}
\hline Factor & $\begin{array}{l}\text { Achieved goal group } \\
(n=39)\end{array}$ & $\begin{array}{l}\text { Nonachieved goal } \\
\text { group }(n=16)\end{array}$ & Total $(\mathbf{N}=55)$ & $P$-value \\
\hline \multicolumn{5}{|l|}{ Sex } \\
\hline Male & $18(46.2 \%)$ & $10(62.5 \%)$ & $28(50.9 \%)$ & 0.271 \\
\hline Female & $21(53.8 \%)$ & $6(37.5 \%)$ & 27 (49.1\%) & \\
\hline Immunocompromised host ${ }^{\mathrm{a}}$ & $23(59.0 \%)$ & $13(81.3 \%)$ & $36(65.5 \%)$ & 0.115 \\
\hline \multicolumn{5}{|l|}{ Hemoculture } \\
\hline Positive & $13(33.3 \%)$ & $9(56.3 \%)$ & $22(40.0 \%)$ & 0.115 \\
\hline Negative & $26(66.7 \%)$ & $7(43.8 \%)$ & $33(60.0 \%)$ & \\
\hline \multicolumn{5}{|l|}{ Final diagnosis } \\
\hline Pneumonia & $15(38.5 \%)$ & $5(31.3 \%)$ & 20 (36.4\%) & 0.614 \\
\hline Hepatobiliary infection & $2(5.1 \%)$ & $\mathrm{I}(6.3 \%)$ & $3(5.5 \%)$ & 1.000 \\
\hline Urinary tract infection & $5(12.8 \%)$ & $3(18.8 \%)$ & $8(14.5 \%)$ & 0.571 \\
\hline Infective Gastroenteritis & $6(15.4 \%)$ & $0(0.0 \%)$ & $6(10.9 \%)$ & 0.165 \\
\hline Skin and soft tissue & $4(10.3 \%)$ & $\mathrm{I}(6.3 \%)$ & $5(9.1 \%)$ & 1.000 \\
\hline Septic arthritis & I (2.6\%) & $0(0.0 \%)$ & $\mathrm{I}(\mathrm{I} .8 \%)$ & 1.000 \\
\hline Osteomyelitis & I $(2.6 \%)$ & $0(0.0 \%)$ & $\mathrm{I}(\mathrm{I} .8 \%)$ & 1.000 \\
\hline Spontaneous bacterial Peritonitis & I (2.6\%) & I (6.3\%) & $2(3.6 \%)$ & 1.000 \\
\hline Septicemia & $9(23.1 \%)$ & $8(50.0 \%)$ & $17(30.9 \%)$ & 0.062 \\
\hline
\end{tabular}

Note: almmunocompromised host includes those with end-stage renal disease, on immune suppressant drugs, diabetes, leukemia, organ transplant host, neutropenic patient (neutrophils $<500 / \mathrm{mL}$ ). 
Table 2 Demographic data

\begin{tabular}{|c|c|c|c|c|c|}
\hline \multirow[t]{2}{*}{ Continuous variable data } & \multicolumn{2}{|c|}{$\begin{array}{l}\text { Achieved goal group } \\
(n=39)\end{array}$} & \multicolumn{2}{|c|}{$\begin{array}{l}\text { Nonachieved goal group } \\
(n=16)\end{array}$} & \multirow[t]{2}{*}{ P-value } \\
\hline & Mean (SD) & Median (P25-P75) & Mean (SD) & Median (P25-P75) & \\
\hline Age $(y r)$ & $63.6(15.6)$ & $62(52-79)$ & $67.3(13.6)$ & $67(57.8-80)$ & 0.405 \\
\hline Initial serum lactate & $3.6(3.7)$ & $24(1.2-4.7)$ & $5.3(5.2)$ & $3.3(I-I I . I)$ & 0.498 \\
\hline Glasgow coma scale score & $12.9(3.8)$ & $15(12-15)$ & $13.4(3.3)$ & $15(12.8-15)$ & 0.652 \\
\hline Hematocrit & $31.7(7.4)$ & $33(26-36.1)$ & $22.4(5.7)$ & $23.5(20.0-26.7)$ & $<0.001$ \\
\hline Time to antibiotic started (door to needle) & I:04 (I:03) & $0: 55(0: 30-1: 10)$ & $0: 58(0: 29)$ & $0: 50(0: 36-1: 22)$ & 0.669 \\
\hline
\end{tabular}

Abbreviations: SD, standard deviation; yr, years.

Sixteen patients in the nonachieved EGDT goal group achieved CVP $\geq 8 \mathrm{mmHg}$ within 6 hours. Only one of them did not achieve MAP $\geq 65 \mathrm{mmHg}$, and nine of them did not achieve urine output $\geq 0.5 \mathrm{~mL} / \mathrm{h}$, and 15 of them did not achieve $\mathrm{ScvO}_{2} \geq 70 \%$ (Table 5).

\section{Secondary outcome}

Of the 39 patients, nine who achieved goal within 6 hours or a survival rate of $76.9 \%$ died. Of the 16 patients who did not achieve goal within 6 hours, 15 who showed a survival rate of $6.3 \%$ died. There was a statistically significant difference of increased mortality rate between the two groups $(P<0.01)$ (Table 6). The need of vasoactive agents and mechanical ventilation was not statistically significant between the two groups. In the nonachieved goal group, $37.5 \%$ of the patients needed blood transfusion compared with $12.8 \%$ in the achieved goal group $(P<0.01)$.

\section{Discussion}

Early hemodynamic optimization is crucial and has an effect on the mortality rate in severe sepsis and septic shock patients. Since EGDT became the standardized treatment for severe sepsis and septic shock in 2001, there are many reports on the implementation of EGDT in the emergency room. Previous research showed that implementation of the EGDT guideline in the emergency room can be successfully done even in a community-based hospital. ${ }^{6}$ The success rates of applying and achieving the EGDT goals were $78 \%-91 \%$, and the mortality rates decreased by $20 \%-60 \%{ }^{4}{ }^{4}$
Therefore, EGDT was implemented in the emergency room of Songklanagarind Hospital in 2010. Patients who presented with fever, aged $\geq 18$ years, and an initial diagnosis of severe sepsis and septic shock according to the Sepsis Campaign Guideline 2008 were treated according to the EGDT guideline by the emergency physicians.

The primary outcome of this study was the success rate of achieving EGDT goal within 6 hours, defined by CVP $\geq 8-12 \mathrm{mmHg}$, MAP $\geq 65 \mathrm{mmHg}$, urine output $\geq 0.5 \mathrm{~mL} / \mathrm{kg} / \mathrm{h}$, and $\mathrm{ScvO}_{2} \geq 70 \%$ according to the original article by Rivers et al. ${ }^{1}$ The original article reported the median time of the CVP goal as 6 hours, MAP goal as 4 hours, and $\mathrm{ScvO}_{2}$ goal as 5 hours. In this study, among the 16 patients in the nonachieved goal group, all achieved CVP $\geq 8-12 \mathrm{mmHg}$ and $93.8 \%$ of them achieved MAP $\geq 65 \mathrm{mmHg}$, but none of them achieved $\mathrm{ScvO}_{2} \geq 70 \%$, which was statistically significant $(P<0.001) . \mathrm{ScvO}_{2}$ indicates whether oxygen delivery is adequate to meet a patient's needs. Tables 1 and 2 list the hematocrits of the patients in the two groups. The mean hematocrits of patients in the achieved goal group and the nonachieved goal group were 31.7 and 22.4, respectively, which was statistically significant $(P<0.001)$. However, there are many reasons for a decrease in the $\mathrm{ScvO}_{2}$ : 1) it indicates that tissues are extracting a higher percentage of oxygen from the blood than normal, 2) the individual's cardiac output is not high enough to meet their needs, and 3) the hemoglobin may be too low.

The secondary outcome in this study was to determine how much EGDT improved the mortality rate in severe

Table 3 Comparison of the mean and median SAP II, APACHE II, and SOFA scores between the two groups

\begin{tabular}{|c|c|c|c|c|c|}
\hline \multirow[t]{2}{*}{ Severity score } & \multicolumn{2}{|c|}{ Achieved EGDT goal group $(n=39)$} & \multicolumn{2}{|c|}{ Nonachieved goal group $(n=16)$} & \multirow[t]{2}{*}{$P$-value } \\
\hline & Mean \pm SD & Median (P25-P75) & Mean \pm SD & Median (P25-P75) & \\
\hline SAP II & $31.9 \pm 26.9$ & $21.3(9.7-55.3)$ & $43.2 \pm 28.5$ & $35.0(|7|-7 \mid .2)$. & 0.0097 \\
\hline APACHE II & $46.0 \pm 23.0$ & $46.0(26.2-63.9)$ & $59.9 \pm 23.8$ & $62.2(40.7-83.5)$ & 0.058 \\
\hline SOFA & $8.8 \pm 2.8$ & $9(7-I I)$ & $10.1 \pm 2.5$ & $10(8-12)$ & 0.105 \\
\hline
\end{tabular}

Abbreviations: SAP II, Simplified Acute Physiology II; APACHE II, Acute Physiology and Chronic Health Evaluation II; SOFA, Sequential Organ Failure Assessment; EGDT, early goal-directed therapy; SD, standard deviation. 
Table 4 Resuscitative procedures and agents

\begin{tabular}{|c|c|c|c|}
\hline $\begin{array}{l}\text { Resuscitative } \\
\text { procedure/agent }\end{array}$ & $\begin{array}{l}\text { Achieved goal } \\
\text { group }(n=39)\end{array}$ & $\begin{array}{l}\text { Nonachieved goal } \\
\text { group }(n=16)\end{array}$ & $P$-value \\
\hline $\begin{array}{l}\text { Vasoactive agent } \\
\text { needed, } \mathrm{n}(\%)\end{array}$ & $38(97.4)$ & $14(87.5)$ & 0.200 \\
\hline $\begin{array}{l}\text { Mechanical ventilation } \\
\text { needed, } \mathrm{n}(\%)\end{array}$ & $16(41.0)$ & 7 (43.8) & 0.852 \\
\hline $\begin{array}{l}\text { Blood transfusion } \\
\text { needed, } \mathrm{n}(\%)\end{array}$ & $5(12.8)$ & $6(37.5)$ & $<0.01$ \\
\hline
\end{tabular}

sepsis and septic shock. The mortality rate in severe sepsis and septic shock can be affected by many factors, such as previous medical illness, cause of sepsis, quality of resuscitation and time antibiotics were given, and severity of the illness. To decrease the bias of the study, the time to initiate antibiotics, initial diagnosis, and severity of illness were recorded (Tables 1 and 2). Tables 1 and 2 list the demographic data that may affect the results of treatment, such as age, sex, immune status, causes of sepsis, initial serum lactate, time to initiate antibiotics, initial hematocrit, and level of consciousness, all of which showed no statistical significance between the two groups. Table 3 lists the results of the severity scores, which showed no statistical significance between the two groups. Table 4 lists the resuscitative procedures and agents that were used, such as vasoactive agents, mechanical ventilation, and blood transfusion. The need of vasoactive agents and mechanical ventilation was not statistically significant between the two groups. However, the need for blood transfusion was quite significant in the nonachieved goal group. This may be because the initial hematocrits were lower in this

Table 5 Target early goal-directed therapy achieved within 6 hours in the achieved goal and nonachieved goal groups

\begin{tabular}{|c|c|c|c|c|}
\hline $\begin{array}{l}\text { Goals } \\
\text { reached } \\
<6 \text { hours }\end{array}$ & $\begin{array}{l}\text { Achieved goal } \\
\text { group, n (\%) }\end{array}$ & $\begin{array}{l}\text { Nonachieved } \\
\text { goal } \\
\text { group, n (\%) }\end{array}$ & $\begin{array}{l}\text { Total, } n \\
(\%)\end{array}$ & $P$-value \\
\hline \multicolumn{5}{|c|}{$C V P \geq 8-12 \mathrm{mmHg}$} \\
\hline Yes & $39(100)$ & $16(100)$ & $55(100)$ & - \\
\hline \multicolumn{5}{|l|}{ No } \\
\hline \multicolumn{5}{|c|}{$\mathrm{MAP} \geq 65 \mathrm{mmHg}$} \\
\hline Yes & $39(100)$ & 15 (93.8) & $54(98.2)$ & 0.291 \\
\hline No & 0 & I (6.3) & $\mathrm{I}(\mathrm{I} .8)$ & \\
\hline \multicolumn{5}{|c|}{ Urine output $\geq 0.5 \mathrm{~mL} / \mathrm{kg} / \mathrm{h}$} \\
\hline Yes & $39(100)$ & $7(43.8)$ & $46(83.6)$ & $<0.001$ \\
\hline No & 0 & $9(56.3)$ & $9(16.4)$ & \\
\hline \multicolumn{5}{|c|}{$\mathrm{ScrO}_{2} \geq 70 \%$} \\
\hline Yes & $39(100)$ & $0(0)$ & 39 (70.9) & $<0.001$ \\
\hline No & 0 & $15(100)$ & $15(27.3)$ & \\
\hline
\end{tabular}

Abbreviations: CVP, central venous pressure; MAP, mean arterial pressure; $\mathrm{ScvO}_{2}$, central venous oxygen saturation.
Table 6 Survival and mortality rates of the achieved and nonachieved goal groups

\begin{tabular}{llll}
\hline Outcome & $\begin{array}{l}\text { Achieved goal } \\
(\mathbf{n}=\mathbf{3 9})(\%)\end{array}$ & $\begin{array}{l}\text { Nonachieved goal } \\
(\mathbf{n}=16)(\%)\end{array}$ & P-value \\
\hline Survived & $30(76.9)$ & $\mathrm{I}(6.3)$ & $<0.00 \mathrm{I}$ \\
Dead & $9(23.1)$ & $15(93.8)$ & \\
\hline
\end{tabular}

group (Tables 1 and 2). The data showed a 23.1\% mortality rate in the achieved goal group compared with $93.8 \%$ in the nonachieved goal group $\left(\mathrm{ScvO}_{2}<70 \%\right)$. The benefits of applying EGDT were also observed in other studies. ${ }^{7,8}$ Puskarich et $\mathrm{al}^{7}$ showed the benefits of EGDT by a decrease in mortality rate from $49 \%$ before implementation of the guideline to $37 \%$ after implementation of the guideline. Huang et $\mathrm{al}^{9}$ showed that the benefits of EGDT were not only a decrease in the mortality rate, but also a decrease in the length of hospital stay and cost. In 2010, a multicenter randomized trial of 300 sepsis patients reported no differences in the in-hospital mortality rate between septic shock patients who were treated to normalized lactate clearance compared with $\mathrm{ScvO}_{2} \cdot{ }^{10}$

The ARISE trial, ${ }^{11}$ and ProCESS trial, ${ }^{12}$ were two recent multicenter trials to determine whether the EGDT protocol could improve the mortality rate compared with usual care group. They concluded that there were no statistically significant differences between the mortality rates and lengths of hospital stay between those two groups. However, the ARISE trial and ProCESS trial defined the usual care group as treated by bedside provider-directed care without protocols. They showed, no actual methods or parameters for resuscitation and no care guidelines. Moreover, the final outcomes showed no statistical significance between the amount of fluid, and $\mathrm{ScvO}_{2}$ at 6 hours after resuscitation.

\section{Conclusion}

The key for the treatment of severe sepsis and septic shock is to optimize the patient's hemodynamic functions. EGDT is a useful tool to guide resuscitation in the emergency room. The success rate of applying EGDT in the emergency room in this study was $70.9 \%$. The data showed that for septic shock patients who achieved the EGDT goals within 6 hours, the mortality rate decreased from $93.8 \%$ to $23.1 \%$ compared with patients who could not achieve the EGDT goals within 6 hours.

\section{Acknowledgment}

The expenditures for this study were supported by the Faculty of Medicine of Prince of Songkla University. 


\section{Disclosure}

The authors report no conflicts of interest in this work.

\section{References}

1. Rivers E, Nguyen B, Havstad S, et al. Early gold-directed therapy in the treatment of severe sepsis and septic shock. $N$ Engl J Med. 2001;345: 1368-1377.

2. Dellinger RP, Carlet JM, Masure H, et al; Surviving Sepsis Campaign Management Guidelines Committee. Surviving Sepsis Campaign guidelines for management of severe sepsis and septic shock. Crit Care Med. 2004;32:838-873.

3. Trzeciak S, Dellinger RP, Abate NL et al. A 1-year experience with implementing early goal-directed therapy for sepsis shock in the emergency department. Chest. 2006;129:225-232.

4. Turi SK, Voh Ah D. Implementation of early goal-directed therapy for septic patients in the emergency department: a review of the literature. J Emerg Nurs. 2013;39(1):13-19.

5. Dellinger RP, Levy MM, Carlet JM, et al. Surviving sepsis campaign: international guidelines for management of severe sepsis and septic shock: 2008. Intensive Care Med. 2008;34:17-60.

6. O’Neill R, Morales J, Juel M. Early goal-directed therapy (EGDT) for severe sepsis/septic shock which components of treatment are more difficult to implement in community-based emergency department? JEmerg Med. 2012;42(5):503-510.
7. Puskarich MA, Marchick MR, Kline JA, Steuerwald M, Jones AE. One year mortality of patients treated with an emergency department based early goal directed therapy protocol for severe sepsis and septic shock: a before and after study. Crit Care. 2009;13(5):R167.

8. Sweet DD, Jaswal D, Fu W, Douchard M, et al. Effect of an emergency department sepsis protocol on the care of septic patients admitted to the intensive care unit. CJEM. 2010;12(5):414-420.

9. Huang DT, Clearmont G, Dremsizov TT, Angus DC, ProCESS Investigators. Implementation of early gold-directed therapy for severe sepsis and septic shock: a decision analysis. Crit Care Med. 2007;35(9):2090-2100.

10. Jones AE, Shapiro NI, Trzeciak S, Arnold RC, Claremont HA, Kline JA; Emergency Medicine Shock Research Network (EMShockNet) Investigators. Lactate clearance vs central venous oxygen saturation as goals of early sepsis therapy: a randomized clinical trial. JAMA. 2010;303(8):739-746.

11. Arise Investigators. Goal-directed resuscitation for patients with early septic shock. N Engl J Med. 2014;371:1496-1506.

12. ProCESS Investigators, Yealy DM, Kellum JA. A randomized trial of protocol-based care for early septic shock. $N$ Engl J Med. 2014;370:1683-1693.

\section{Dovepress}

\section{Publish your work in this journal}

Open Access Emergency Medicine is an international, peer-reviewed, open access journal publishing original research, reports, editorials, reviews and commentaries on all aspects of emergency medicine. The manuscript management system is completely online and includes a very quick and fair peer-review system, which is all easy to use.
Visit http://www.dovepress.com/testimonials.php to read real quotes from published authors. 